\title{
LA EXPERIENCIA JURÍDICA
}

SUMARIo: 1. La aparición o re-aparición de la experiencia juridica. 2. Aventuras de la noción de experiencia. 3. Algunos ejemplos del sentido kantiano y del positivista del concepto de "experiencia juridica". 4. Nuevas acepciones de "experiencia juridica". A) Gurvitch. B) Capograssi. C) Carnelutti. D) Cossio. E) Holmes. F) Husson. G) Bataglia. H) Perticone. I) Giuliani. J) Alusiones a otros iusfilósofos (Reale, Czerna, Guzmāo, Terán Mata, Garcia Maynez, Cahn y Bagolini). 5. Ensayo de algunas puntualizaciones y de algunos esclarecimientos sobre los temas de la "experiencia juridica".

\section{La aparición o re-aparición de la experiencia juridica}

Este epígrafe habla de "aparición" o "re-aparición" de la experiencia jurídica, porque estas palabras, aunque añejas, han sido y siguen siendo empleadas en sentidos muy diferentes. Aquí se tratará de exponer algunas de las nuevas acepciones - no todas ellas iguales- en que este enunciado se presenta en varios estudios filosófico-jurídicos de los últimos lustros, tales como los de Gurvitch Capograssi, Cossio, Reale, Husson, Bataglia, Perticone, Bagolini, y otros. Y mucho antes que los iusfilósofos mencionados, esta locución "experiencia jurídica" habla sido usada por Holmes y por Petrazycki, y con unos sentidos muy diferentes - sentido kantiano- por Stammler, por Kelsen, por Sander y por Cossio.

Hablando con toda sinceridad, confesaré que, al estudiar el pensamiento de los autores que recientemente han empleado el concepto de "experiencia jurídica", en mis primeros encuentros con los nuevos usos - por cierto muy varios - de estas palabras, sentí una desazón, algo así como un aturdimiento, como el hallarme sumido en una neblina, que dejaba difuminados algunos conceptos básicos para el pensamiento jurídico. Y, no obstante, al esforzarme por rumiar intelectualmente lo que pudiese haber debajo de esta locución "experiencia jurídica", empleada - aunque en diversos sentidos- por Hussón, Bataglia, Perticone, Bagolini, y otros, he llegado a darme cuenta de que detrás de esas palabras hay el barrunto de algo que puede llegar a ser muy importante para la Filosofía y para la Sociología del Derecho. Sólo que, a mi entender, ese "algo importante" necesita ser aclarado, precisado con rigor. Para ello, urge no sólo desenmarañar varias nociones que han sido mezcladas, clarificar algunos conceptos, sino también tomar en consideración otras aportaciones filosófico-jurídicas de nuestros días - por ejemplo, de Legaz y Lacambra, Roscoe Pound, Erich Fechner, Edmond Cahn - las cuales, aunque no usan la expresión "experiencia jurídica" se refieren a puntos que pueden ser decisivos para clarificar lo que algunos han presentido al servirse de estas palabras, aunque no consiguiesen descifrarlo suficientemente. 


\section{Aventuras de la noción de experiencia}

A la palabra "experiencia" le ha acontecido lo que otros muchos vocablos en el campo de la filosofía: el hecho que ha sido usada en acepciones muy diferentes $y$, además, el hecho de que se la han ido acumulando otros sentidos. Ahora bien, hubo épocas en las que de esa variedad de significados, uno de ellos adquirió uso, si es que no exclusivo, por lo menos predominante.

Así, prístinamente, experiencia denota el conocimiento directo de algo dado ante nosotros. Ese algo dado puede ser un dato sensorial, un estado de conciencia, una idea o principio evidente, una realidad trascendente (Dios en la contemplación de los místicos), unas estructuras finalistas, o cualquier otro objeto que se nos presente de manera directa.

También es antigua la acepción de la palabra experiencia como indicadora de las enseñanzas que el ser humano va sacando de lo vivido por él mismo y de lo vivido por sus prójimos - antepasados o contemporáneos-, enseñanzas derivadas de lo experimentado, y que suelen producir una especie de entrenamiento o de mayor destreza para tratar problemas prácticos -e incluso también teóricos, pues cabe hablar con razón de la experiencia en quehaceres intelectuales, por ejemplo, de la experiencia de errores cometidos, la cual nos alecciona para no seguir vías que se mostraron como equivocadas o muertas. Tal es el sentido popular que esta palabra tiene cuando se habla de "una persona de o con experiencia", y de que "la experiencia enseña a hacer las cosas cada vez de mejor modo"; y es el sentido que se subraya en las filosofías de Dilthey (razón histórica), de John Dewey ("trial and error experience" y razón experimental), de José Ortega y Gasset (razón vital y razón histórica), y en mi doctrina del "logos de lo razonable".

Volviendo ahora a la noción de experiencia como conocimiento directo de algo dado, veamos algunas de las aventuras padecidas por este concepto. Bien sabido es que el sentido de la palabra "experiencia" fue sobremanera estrechado, para denotar con ella sólo la "experiencia sensible", externa (sensorial) e interna, y aun preferible o exclusivamente, la externa. Esto sucedió incluso en algunos momentos o en algunas facetas del pensamiento griego antiguo, pero sobre todo en el llamado empirismo moderno (Locke, Hume, etc.) y en la Crítica de la Razón Pura de Kant. También, en el uso habitual reinante en el ámbito de las ciencias naturales, "empíricas por antonomasia", esto es, constituidas sobre la base de la experiencia sensible.

Perdone el lector que en este trabajo, el cual pretende aportar algo nuevo, aunque ese algo nuevo sea muy poco - sencillamente algunos esclarecimientos - haya recordado puntos tan rudimentarios, harto conocidos por un estudiante primerizo. Sin embargo, tal vez fuesen convenientes esas remembranzas, para que, ante todo, resalte debidamente lo que se subrayará enseguida - que es asimismo algo bien sabido-, el hecho de que en la mayor 
parte de las doctrinas filosóficas del siglo $\mathrm{xx}$ se ha vuelto al sentido originario de la noción de experiencia, como conocimiento de algo dado directamente a la conciencia -no sólo de algo sensible, sino también de algo ideal, y también, de algo metafísico. Pero aquellas remembranzas fueron oportunas, además y especialmente, para las aclaraciones preliminares -sólo prologalessobre qué debemos entender por "experiencia jurídica".

La evocación de algunas de las peripecias por las que ha pasado la noción de "experiencia" podrá servir para desentrañar el sentido más o menos preciso, o menos o más confuso, con que algunos de los autores contemporáneos - que mencioné al principio- han usado esta frase: "experiencia jurídica".

E incluso quizá sea fructuoso insistir sobre el hecho, ya apuntado, de que en la mayoría de las doctrinas filosóficas de nuestros días se ha ido ensanchando y ensanchando, más y más, la noción de experiencia, con lo que no sólo se ha vuelto a la comprensión antigua que abarcaba este término, sino que se ha dado al mismo nuevas extensiones. Así, al lado o más allá de la experiencia sensible y de la psicología, se habla de una experiencia de ideas evidentes, de una experiencia de valores, de una experiencia metafísica, de una experiencia religiosa, de una experiencia moral y de una experiencia jurídica. En todos esos casos, al hablar de "experiencia" se intenta manifestar que no se trata de objetos elaborados por la mente, que no se trata de aportaciones del sujeto pensante, sino que, por el contrario, se trata de objetos pre-existentes, los cuales nos aparecen como dados ante nuestra conciencia, de un modo previo a las interpretaciones que nuestra inteligencia pueda añadir después sobre tales objetos.

Así, se ha ampliado enormemente la extensión que el concepto de experiencia tuvo en la conciencia y en la filosofía modernas -como experiencia sensorial一, añadiéndole áreas situadas más allá del ámbito de nuestra percepción exterior y de las ciencias naturales.

3. Algunos ejemplos del sentido kantiano y del positivista del concepto de "experiencia juridica"

Rudolf Stammler, Fritz Sander, Hans Kelsen, y otros, usan la expresión "experiencia jurídica" para señalar el conocimiento del Derecho positivo -vigente, o histórico de otra época. Al fin y al cabo, éste es el sentido con que emplean tal expresión todos quienes se refieren a la toma de contacto mental con el Derecho positivo que está ahí ante nosotros. Sólo que Stammler, Kelsen y Sander se preguntan en sentido kantiano, sobre el plano de la gnoseología o epistemología, por cuáles sean las condiciones que hacen posible este conocimiento del Derecho, las que son a la vez condiciones de los objetos jurídicos mismos -en la plena ortodoxia del idealismo trascendental. De esta suerte, por ejemplo, Stammler ${ }^{1}$ se propuso indagar el concepto 
universal del Derecho y las categorías jurídicas fundamentales, que constituyen las condiciones previas de toda experiencia jurídica, es decir, de todo conocimiento del Derecho, y, a la vez, las condiciones de los objetos jurídicos.

Por otra parte, y aunque de diferente manera, también Kelsen ${ }^{2}$ sostiene que el objeto Derecho, la forma normativa intrínsecamente dotada de coercitividad, es el producto de un especial método normativo, el objeto que se constituye como resultado de éste.

Y, si bien por vías muy diversas y de modo bastante deleznable, Fritz Sander ${ }^{3}$ quiso elaborar una teoría de la experiencia jurídica, orientándose hacia la Critica de la Razón Pura de Kant, de tal suerte que rechaza por entero los puntos de vista normativos, teleológicos y éticos, y aspira a constituir la ciencia jurídica sobre el patrón de las ciencias matemáticas de la naturaleza.

Es oportuno mencionar en este contexto el positivismo extremista, el super-realismo desbocado de las escuelas escandinavas actuales (Hagerstrom, 4 Olivecrona, ${ }^{5}$ Lundstedt, ${ }^{6}$ Ross, ${ }^{7}$ etc.), que intentan reducir todo el conocimiento y toda la realidad de lo jurídico a un estudio psicológico de los mecanismos mentales y sociales del "sentirse obligado", del "sentirse autorizado", y que aspiran a edificar una ciencia natural del Derecho, de la cual se hayan eliminado totalmente las nociones de norma, de imperativo, de obligación, de derecho subjetivo o facultad; en suma, que en la teoría jurídica quieren estudiar única y exclusivamente unos especiales nexos de causalidad psicológica en la vida social.

1 Cfr. Rudolf Stammler, Lehrbuch der Rechtsphilosophie, 1921. Véase también la exposición sobre Stammler, en Recaséns Siches (Luis), Panorama del Pensamiento Juridico en el Siglo XX, Ed. Porrúa, México, 1969, tomo I, págs. 48-78.

2 Hans Kelsen, Hauptprobleme der Staatsrechtslehre entwickelt aus dem Lehre vom Rechtssatz, 1911; Allgemeine Staatslehre, 1925; Reine Rechtslehre. Mit einem Anhang: Das Problem der Gerechtigkeit, Zweite, vollständig neu bearbeitete und erweiterte Auflage, 1960. Véase también la exposición y crítica sobre Kelsen, en Recaséns Siches, ob. cit. en la nota precedente, págs. 137-222.

3 Cfr. Fritz Sander, Rechtsdogmatik oder Theorie der Rechtserfahrung?, 1921; Staat und Recht. Prolegomena zu einer Theorie der Rechtserfahrung, dos volúmenes, 1922; Die transzendentale Methode und der Begriff des Rechtsverfahrens, en Zeitschrift für öffentliches Recht und Völkerrecht, vol. I.

4 Cfr. Axel Hagerstrom, Inquiries into the Nature of Law and Morals, 1959. Véase: Recaséns Siches, ob. cit., pág. zo4.

5 Cfr. Herman Olivecrona, Law as Fact, 1939; Gesetz und Staat, 1940; Realism and Idealism: Some Reflections on the Cardinal Point in Legal Philosophy, en "New York University Law Review", 1951; Legal Language and Reality, en Essays in Jurisprudence in Honor of Roscoe Pound, 1962. Véase también: Recaséns Siches, ob. cit., págs. 305-314.

6 Cfr. V. Lundstedt, Superstition or Rationality in Action for Peace: A Criticism of Jurisprudence, 1925; Die Unwissenschaftlichkeit der Rechtswissenschaft, 1932; El Derecho y La Justicia, en el volumen "El hecho del Derecho", 1956. Véase: Recaséns Siches, ob. cit. pág. 304.

7 Alf Ross, Theorie der Rechtsquellen, 1928; Towards a Realistic Jurisprudence. Sobre Ross, véase: Recaséns Siches, ob. cit., págs. 303-304. 
Ahora bien, he mencionado lo que "experiencia jurídica" significa en Stammler y en Kelsen, porque reconozco que las teorías de esos dos grandes maestros neokantianos, a pesar de que cada día me vaya sintiendo más alejado de ellas, tienen sentido, y además son congruentes con los respectivos supuestos de los que partieron uno y otro. Pero el sentido en que esas dos teorías hablan de "experiencia jurídica" no es relevante para el propósito del presente estudio. Ninguna de ambas habría suscitado en mí la necesidad de ofrecer especiales meditaciones sobre lo que puedan significar otras varias cosas que otros autores más recientes llaman "experienca jurídica". A Sander me referí como una incidencia de corto alcance. Por lo que respecta a las escuelas escandinavas, aludi de pasada a ellas, como simple anécdota intrascendente; sobre todo intrascendente para la filosofía jurídica, aunque tal vez tengan algún interés —-desde luego muy limitado- para determinados capítulos de la sociología del Derecho.

\section{Nuevas acepciones de "experiencia juridica"}

Mientras que las doctrinas referidas bajo el epígrafe antecedente hablan de "experiencia jurídica" como conocimiento del Derecho positivo, en cambio, esta misma expresión trata de significar otras cosas en algunas nuevas teorías. Ya dije que, a mi parecer, algunas de esas nuevas teorías que introducen la noción de experiencia jurídica — cada una de ellas con un especial sentido- han barruntado algo que merece tomarse en cuenta muy seriamente, aunque sea necesario someter ese algo a una depuración crítica. Pero antes de emprender, o mejor dicho de iniciar, esa tarea de acrisolar un nuevo concepto, o una nueva acepción de "experiencia jurídica", es pertinente ofrecer aquí, aunque sea de un modo muy breve, muy somero, algunas de las principales versiones que han sido presentadas de esta nueva noción.

\section{A) Gurvitch}

Georges Gurvitch,8 por una parte, distingue claramente entre Sociología jurídica y Filosofía del Derecho, pues aunque ambas se refieren a la misma esfera de lo espiritual - los valores que deben inspirar al Derecho-, tratan esta esfera desde dos puntos de vista diversos: la Sociología jurídica, en función de la realidad social; y la Filosofía del Derecho se ocupa de esta esfera tomándola en sí misma, de un modo intrínseco y en relación con otros sectores del espíritu, contemplado éste en su validez objetiva. Mas, por otra parte, Gurvitch propugna una intima y mutua colaboración entre Sociología jurídica y Filosofía del Derecho. Para ambas, según Gurvitch, tiene decisivo

8 Cfr. Georges Gurvitch, L'Experience Juridique et la Philosophie Pluraliste du Droit, 1935; Sociologie Juridique, 1940. Sobre Gurvitch, véase: Recaséns Siches, ob. cit., págs. $134^{-1} 3^{6}$. 
alcance e imprescindible necesidad la "experiencia jurídica". Se trata de una experiencia enriquecida con todos los datos inmediatos del mundo espiritual y del mundo ideal. Esa experienca jurídica de los datos espirituales o ideales, que se realizan en lós hechos, existe virtualmente siempre, bien como fundamento inconsciente, bien deformada bajo una costra conceptual, reflejada o interesada en el interior de todas las manifestaciones de la vida jurídica. Así, dentro de la psicología del legislador, de la del juez y también de la de las partes interesadas en un pleito; $y$, asimismo, todavía con mayor generalidad, en la psicología de todos los participantes en la vida jurídica de un grupo cualquiera.

Dice Gurvitch que la experiencia jurídica se presenta con un carácter dramático, porque está tejida con antinomias irreductibles. Hallamos valores espirituales que se manifiestan en hechos sensibles; y también valores éticos que se logifican. Siempre, pues, encontramos un entrecruce de valores y de hechos, irreductibles entre sí.

Según Gurvitch, la experiencia juridica inmediata, que es infinitamente variable, tanto en sus contenidos espirituales como en los sensibles, es la que permite aprehender la realidad del Derecho; y es la que sirve de base común a la Filosofía del Derecho, a la Sociología jurídica y a la ciencia dogmáticopositiva o técnica del Derecho. Esa experiencia jurídica inmediata integral es intermedia entre la experiencia de lo sensible y la de lo espiritual; y es intermedia también entre la experiencia ética y la experiencia de ideas lógicas; y está constituida por actos colectivos de reconocimiento frio de las situaciones sociales sensibles que realizan valores positivos de justicia. Pero, puesto que son múltiples los aspectos de la justicia, y como quiera que éstos se cumplen en realidades sociales muy diferentes, por eso hay una superlativa variedad en la experiencia jurídica y en sus datos, así como hay también un cambio histórico. Esa variedad y ese cambio se dan en función de la diversa dosificación entre la experiencia de lo sensible y la experiencia de lo espiritual, y también en función del grado de actualidad o de virtualidad con que son vividos los estratos o escalones, más o menos profundos, de la experiencia jurídica.

En la experiencia jurídica hay hechos.dados, hay valores jurídicos efectivamente vividos, hay ilusiones y programas - proyecciones subjetivas de la colectividad-, y hay estructuras ideales objetivamente válidas. Sin embargo, a pesar del pluralismo, hay una unidad en la diversidad: una unidad que consiste en la posibilidad de que todas esas varias fuentes de experiencia jurídica se integren en un todo más amplio, en el todo infinito de la justicia, dentro de una época: así, una comunidad económica o política debe poder integrarse en una comunidad nacional, y ésta en una comunidad internacional. En todo eso manifestado por Gurvitch me parece que hay algo importante, más bien presentido u oteado a distancia, pero aún no suficientemente claro, al menos en mi opinión. Algo similar acontece con las contribuciones 
de otros autores a las que voy a referirme a continuación, y de las que también se puede aprovechar algunos estímulos de positivo interés.

\section{B) Capograssi}

Giuseppe Capograssi ${ }^{9}$ se interesa, no tanto por las formas de conocimiento, sino más bien y sobre todo por el contenido de lo real, especialmente de la vida humana. Para Capograssi, "experiencia" significa el encuentro con la realidad toda. Capograssi no se propone descubrir cómo se piensa el Derecho, sino cómo se hace el Derecho. Ahora bien, el Derecho va formándose en, a través y mediante la experiencia jurídica. Busca el Derecho como idea y como energía humanas vivientes. La acción se enriquece a través de su progresivo objetivarse en las relaciones interindividuales, en la familia, en la patria, en la humanidad. Se trata de la exigencia intrínseca de la acción de adecuarse a sí misma, de ser sí misma, esto es, de no negar su conexión con la vida total del sujeto en el cual ella nace. Esta exigencia se manifiesta con el imperativo jurídico, que es una parte de la ley de la acción. Pues la ley de la acción se divide en dos: la ley jurídica y la ley moral. El mal es algo negativo, es la acción no cumplida. Puesto que la amenaza del mal se da contra la acción y contra el agente, el imperativo jurídico prescribe salvar la acción; y el imperativo moral, salvar al agente. La experiencia ética es la experiencia de los medios para defenderse frente al mal. Salvar la acción es tan importante, tan necesario, como salvar al agente. En lo jurídico, la acción se adecúa exactamente a la voluntad. Aunque la unidad del mundo humano se realiza sólo por la ley moral, mediante la actuación de una voluntad buena, que sea tal, cualesquiera que sean las condiciones de la acción, en cambio, el imperativo jurídico está ligado a las condiciones de la acción.

Capograssi analiza la experiencia jurídica lo mismo en la múltiple complejidad de ésta, que en su profunda unidad. El principio del Derecho lo hallamos en el interior mismo del mundo jurídico, como acción en su universalidad intrínseca (ley), en su concreción particularizada (observancia de la ley), y en la conciencia de su unidad (Estado). Ese principio es la acción como verdad que debe ser realizada. De la afirmación enérgica de la ley surge el Estado, el mandato al órgano para la aplicación de la sanción. El Estado surge como voluntad de construir la unidad sobre la multiplicidad.

Dice Capograssi que entre ciencia y experiencia jurídicas hay una distinción, pero no una oposición. La ciencia no es sino la experiencia misma, en tanto que ésta cobra conciencia de sí misma. Para entender la índole de la experiencia jurídica, es necesario reclamar el testimonio tanto de la ciencia como de la experiencia misma, es necesario lograr la autoconciencia. Sería

9 Cfr. Giuseppe Capograssi, Studi sull'experienza giuridica, 1932; Il problema'della scienza del diritto, 1937. Véase También Recaséns Siches, ob. cit., págs. 280-29o. 
algo rarísimo que el conocimiento producido por dicha experiencia no supiese qué cosa es, y que tuviera necesidad de preguntárselo al filósofo del Derecho, quien está fuera de la labor de tal experiencia, y no participa en el esfuerzo que se da en el drama de ella. Frente a la vida del Derecho, la ciencia que quiere captar esa vida, antes de proceder a la elaboración de conceptos, vuelve su atención hacia el mandato, en el cual reconoce "el centro en torno del cual la realidad de esta experiencia debe ser organizada para comprenderla". Sucesivamente, la ciencia traduce en conceptos los principios que forman el contenido de los mandatos, ordenando esos conceptos en grupos cada vez más generales, en los que la ciencia advierte una unidad, porque tales conceptos son las determinaciones de un elemento universal: la voluntad de unidad superior a todas las voluntades cambiantes. Así, se efectúa el tránsito de la voluntad subjetivada a la objetividad de la experiencia.

La experiencia jurídica, según Capograssi, aparece en su inmediatez como "una experiencia de mandatos y de obediencia, en reciproca conexión". Esta experiencia jurídica es una parte de la total experiencia práctica, en la cual la voluntad es el protagonista declarado y visible. Nunca hay una obediencia que, en algún sentido, no sea también adhesión al mandato.

La experiencia jurídica muestra una dirección axiológica: el valor fundamental es el individuo, ya que "el mundo histórico se forma, porque la voluntad del individuo se abre camino en el medio de lo concreto". Se trata del individuo real, del individuo empírico, que ha sido ignorado por tantas investigaciones contemporáneas.

Tal vez esas manifestaciones de Capograssi sean nada más que tanteos, nada más que direcciones de exploración, todo lo cual no haya llegado a un suficiente grado de madurez y de diafanidad. Pero, aunque nos aventurásemos a formular tal juicio, entiendo que de esos ensayos de Capograssi, aquí nada más que aludidos, se puede y aún se debe retener los siguientes puntos: A) Experiencia juridica es la conciencia que lleva a hacer Derecho, a producir el mundo de lo jurídico. B) El Derecho se hace en la vida humana. $C$ ) El Derecho no es primariamente un producto intelectual, sino el resultado de actos de voluntad. D) Es una voluntad que se objetiva precisamente en los productos jurídicos: ley, observancia de ésta, imposición de sanciones, unificación en el Estado. E) La experiencia jurídica consiste originariamente en la experiencia de mandatos, y en el sentimiento de obediencia a éstos en indisoluble conexión. F) En todas esas experiencias hay una dirección estimativa, la voluntad de realizar unos valores dentro de un determinado medio social concreto, con la intención de servir a las necesidades del individuo real. $Y$ yo me atrevería a añadir que todos esos puntos implican que la experiencia juridica es la auténtica fuente de los contenidos juridicos y es el motor que lleva a la producción del Derecho en general, y en concreto también de cada norma juridica en particular. 


\section{C) Carnelutti}

También Francesco Carnelutti ha dicho incidentalmente algunas cosas importantes respecto de la experiencia jurídica. En su Metodologia del Derecho, Carnelutti no se atiene a la distinción comúnmente admitida entre Ciencia dogmático-técnica del Derecho positivo y Filosofía del Derecho (comprensiva ésta de una teoría fundamental o general del Derecho, y de una doctrina estimativa o axiológica), sino que, por el contrario, trata de investigar unitaria y comprensivamente las reglas de la experiencia juridica, que son las reglas del obrar juridico, las cuales abarcan no sólo lo que se refiere a cómo maniobrar con el Derecho (cómo cumplirlo, cómo individualizarlo judicialmente, etc.), sino también a cómo fabricarlo o elaborarlo, y a cómo conseguir el éxito apetecido en esos dos tipos de faenas.

Este enfoque de Carnelutti parece implicar el supuesto de que hay vivencias, experiencias, que son comunes a la producción del Derecho, a su cumplimiento, a su individualización jurisdiccional, en suma, experiencias que actúan a la vez como estímulo y como orientación de la vida jurídica.

\section{D) Cossio}

Carlos Cossio ${ }^{10}$ opera también con un concepto de "experiencia jurídica", pero este concepto cossiano es acuñado más bien en el plano de la epistemología jurídica y acaso también con algunas proyecciones ontológicas. Por eso, aunque tal concepto sea diferente de los formados por Stammler y Kelsen, pertenece a una problemática semejante a las de estos dos. Consiguientemente, en mi opinión, no ofrece estímulos para indagar el tema mentado con la misma expresión "experiencia jurídica", en las incitaciones o en los barruntos que estoy reseñando de modo somero en esta parte del presente estudio y que pueden servir para lograr un nuevo concepto de "experiencia jurídica", el cual aclare mejor muchos temas capitales de la filosofía y de la sociología del Derecho, y supere añejas nociones, que tal vez debamos declarar caducas, y abra nuevos horizontes al pensamiento jurídico. Sin embargo, y a pesar de que, para mi propósito en la presente indagación, la doctrina de Cossio no se me antoja fecunda ni siquiera relevante, aludiré a ésta con una brevísima referencia. Según Cossio, lo que él llama "experiencia jurídica" se constituye con tres componentes: $1^{\circ}$ ) una estructura de lógica del deber ser, a partir de la forma imputativa "dado A, debe ser B". $2^{\circ}$ ) Un contenido dogmático, que consiste en elementos empíricos, dados por la norma positiva. $\left.3^{\circ}\right)$ Una valoración de justicia o de injusticia, que encarna en aquellos con-

J0 Cfr. Carlos Cossio, La Teoria Egológica del Derecho y el Concepto de Libertad, 1944; Panorama de la Teoría Egológica del Derecho, 1949; Teoría de la Verdad Juridica, 1954 . 
tenidos dogmáticos. Pero quizá pueda tener más interés la doctrina de Cossio, que él llama "vivencia de la contradicción" en la mente del juez, de la cual me he ocupado ampliamente en mi libro Nueva Filosofia de la Interpretación del Derecho (Fondo de Cultura Económica, México, 1956).

\section{E) Holmes}

El famoso magistrado norteamericano Oliver Wendell Holmes, ${ }^{11}$ padre, o mejor dicho abuelo, de varias corrientes del pensamiento jurídico anglosajón contemporáneo, afirmó rotundamente, ya a fines del siglo pasado, que "la vida real del Derecho no ha consistido en lógica sino en experiencia"; y "que las necesidades sentidas en cada época, las teorías éticas y políticas predominantes, las intuiciones en que la acción política se ha inspirado, sea aquellas confesadas explícitamente, sea otras inconscientes, e incluso los prejuicios que los jueces albergan, al igual que otras gentes, han tenido que ver mucho más que los silogismos en la determinación de las normas para gobernar a los hombres".

Aquí Holmes no da un concepto de la "experiencia jurídica"; pero sí menciona algunos de los componentes que intervienen en ésta, concebida como fuente de los contenidos de las normas. Por eso, tales expresiones de Holmes, aunque rudimentarias, van por el inicio del camino que puede llevarnos a hallar el concepto de "experiencia jurídica", en tanto que motor de la produccón del Derecho en general, y de cada norma jurídica en particular, y como orientador de sus contenidos concretos. Conviene recordar, a este respecto, que Holmes recalcó que el crecimiento del Derecho aporta cosas nuevas, las cuales se fundan en el subsuelo de nuevos hechos sociales, de nuevas experiencias humanas, de nuevas necesidades, de nuevas convicciones, de nuevos ideales y de nuevas aspiraciones.

\section{E) Husson}

Quien ha producido la contribución más sustanciosa para establecer el concepto de experiencia jurídica, en el sentido en que de él se trata en el presente estudio, es Léon Husson. ${ }^{12}$ Sostiene Husson que toda creación, al igual que toda interpretación de una norma jurídica, implica una triple experiencia: el percibir una situación social; la conciencia, al menos implícita, de un conjunto de valores; el intento de artificios libremente imaginados para ajustar aquella situación a estos valores. Husson se pro-

11 Cfr. Oliver Wendell Holmes, Holmes Collected Papers, 1920; Julius J. Marke, The Holmes Reader (Selected and Edited by...), 1955.

12 Cfr. Léon Husson, Les Transformations de la Responsabilité: Etude sur la Pensé Juridique, 1947. Véase para una más amplia exposición del pensamiento de Husson: Recaséns Siches, ob. cit., págs. $843-873$. 
pone averiguar cómo funciona la mente jurídica, la mente del legislador, la del abogado, la del juez y la del científico del Derecho.

Husson afirma, muestra y demuestra que el trabajo del jurista de ninguna manera se reduce a las operaciones lógicas mediante las cuales suele expresarse externamente de un modo ficticio. Lo que en el Derecho pueda haber de lógica tradicional —que es poco- se halla subordinado a otras operaciones mentales, y regulado por éstas. Es así, porque el Derecho no es un sistema hipotético-deductivo, sino que, por el contrario se refiere a unas realidades dadas, a unos conflictos de intereses que surgen en la vida social; y apunta a aplicar a éstos una regla de justicia, que responde a una aspiración profunda de nuestro ser humano. Las exigencias de justicia antes de ser pensadas son sentidas; y es precisamente en sus aplicaciones concretas como las captamos mejor. Toda la investigación de Husson, muy rica en temas, muy rigorosa, desemboca en la noción de una "experiencia jurídica". El propósito de Husson es analizar esa experiencia jurídica.

Por de pronto, Husson reconoce con franqueza que la noción de "experiencia jurídica" está lejos de ser perfectamente clara; y que ella suscita resistencias y malentendidos. Esto mismo es lo que yo he declarado al comienzo del presente estudio, diciendo además que mi mente, durante algún tiempo tropezó con esas resistencias y se sintió azorada, aunque al fin creo que me he percatado de que éste es un tema básico, y de que requiere serios esfuerzos para aclararlo y para desenvolverlo.

Dice Husson que el núcleo de la más amplia noción de experiencia se halla en dos conceptos. Por una parte, en el concepto de un contacto con la realidad, de un enriquecimiento que proviene desde fuera, en suma de un dato. Por otra parte, en el concepto de un ensayo, de un intento, de una tentativa, de un probar, lo cual, a diferencia de lo denotado por el primer concepto, señala un despliegue de actividad. Pero estos conceptos distintos se vinculan entre sí en la acepción popular del vocablo "experiencia". El lenguaje corriente habla de la experiencia de datos, de la experiencia de la enfermedad que se padece, pero habla también de las experiencias que uno emprende, de las experiencias de las propias fuerzas, de las experiencias como ensayos de acción sobre la realidad - de las cuales se sacan lecciones. Ahora bien, en los dos sentidos en que se emplea la palabra experiencia hay algo común, a saber: un encuentro con lo real, y, por así decirlo, un duelo, en el cual nos medimos a nosotros mismos con lo real. En ese encuentro o tropiezo con la realidad, solemos además intervenir en ésta, "ponemos las manos en la masa", nos lanzamos a una empresa. Así, la experiencia es por de pronto un "saber" de algo dado; y, en segundo lugar, un "saber hacer", adquirido por la práctica de intervenir en el manejo de eso dado. Ahora bien, a pesar de tal denominador común, se dan muchísimas diversidades 'en cuanto a la extensión del concepto de experiencia, en 
cuanto a las formas de la misma, en cuanto a la índole de los objetos y de las acciones, diversidades que apenas pueden todas ellas formar un género. Por eso, la palabra experiencia no es un término unívoco, sino más bien un término análogo o analógico, como dirían los escolásticos.

Husson analiza los diversos aspectos y planos de la "experiencia juridica". Primero, examina la formación de las costumbres y el arbitraje, pues las unas y el otro son las formas espontáneas del Derecho positivo.

Después, Husson se ocupa de la experiencia jurídica en la legislación, buscando apoyo en algunas observaciones hechas ya por Portalis. El legislador debe fundarse sobre instituciones existentes, y no modificarlas sino con mucha prudencia, pues tiene que habérselas con hombres reales, concretos, infinitamente complejos, en los cuales la naturaleza de la especie se realiza de modos muy diversos. Además, el cambio histórico va presentando nuevas situaciones y, con ellas, nuevos problemas. Por eso, es indispensable la jurisprudencia, englobando bajo este nombre la ciencia y el arte del Derecho por entero, tal y como ambos son profesados por los jurisconsultos; en suma, es absolutamente necesaria la interpretación.

Según Husson, la experiencia jurídica, en el sentido más fuerte y plenario del término, incluye un ensayo, un tanteo para lograr el mejor procedimiento de resolver unos problemas prácticos, y un poner a prueba esos procedimientos creados libremente, respecto de los cuales es imposible prever todas las incidencias que puedan suscitar; y cuyo éxito depende no sólo de su propio valor, sino también de la docilidad o de la resistencia que encuentre en las realidades sociales concretas.

Husson considera la originalidad de la experiencia jurídica, en contraste con la experiencia sensible de los meros hechos naturales. Mientras que la sensible se limita a la mera constatación material, por el contrario, la experiencia jurídica plantea problemas de conducta práctica, y demanda solución a esos problemas, los cuales reciben su sentido y su alcance precisamente por la intervención de un elemento ético, por la reacción de la conciencia ética.

Siguiendo las líneas de iusnaturalismo escolástico, Husson recalca que, puesto que el hombre no es el autor de su naturaleza, él no puede elegir sus fines esenciales. Pero le queda la alternativa de comprenderlos y de adaptarse a ellos, según cada una de las circunstancias, para conseguir su máximo desarrollo en cada caso, dentro de los límites de lo concretamente posible. Por eso, el Derecho es a la vez algo dado y construido, como ya dijo Géry. 


\section{G) Bataglia}

Felice Bataglia ${ }^{13}$ se propone averiguar cuál sea el principio por virtud del cual se constituye la experiencia jurídica, y que anima y suscita, promueve y constituye, alimenta y estimula el mundo jurídico, real y variado. Este mundo jurídico, en su totalidad, se manifiesta dentro de ese principio, a través de leyes e instituciones, convicciones y sentimientos, voluntad obligada y voluntad pretensora, en suma, leyes e ideas, hombres frente a hombres, y constituciones humanas.

Bataglia pretende concebir el Derecho no como una forma capaz de albergar cualquier contenido, sino como un principio ontológico, pletórico de contenido, y presente en toda la experiencia que podamos calificar como jurídica. La práctica, planteada como juridicidad objetiva, se constituye por el hecho de que el yo individual y el tú individual se presentan como universales, a través de conocimientos mutuos, que son, en tanto que tales, éticos. Ética y juridicidad se ligan, pero no se confunden. Ese principio ontológico es no sólo el principio para el conocimiento del Derecho, sino que es además, antes y sobre todo, el principio que produce la experiencia juridica, como realidad, y que crea al Derecho.

Bataglia niega que por razón de un supuesto concepto formal del Derecho, cualquiera experiencia contenida dentro de esa forma sea jurídica. Por el contrario, sostiene que el Derecho se revela a sí propio, es auténticamente Derecho; cuando actualiza el valor humano de lo justo. Ahora bien, Bataglia concibe esa realización de lo justo por las vías de un historicismo abierto, es decir, pretende construir una nueva razón en la experiencia, una razón que se adecúe a la vida y a la historia.

\section{H) Perticone}

Giacomo Perticone ${ }^{14}$ ha elaborado una filosofía jurídica basada en la "filosofía de la acción". Nuestra acción, nuestra vida, revela nuestro ser auténtico, el cual, al obrar, no sólo se afirma en su particularidad, sino que también se afirma en su valor superindividual, esto es, en su valor objetivo. El resultado- de la acción humana nunca puede adecuarse por entero al ansia por la cual la acción está inspirada. De esto se sigue la búsqueda de la superación.

La acción se presenta, pues, como una síntesis de un ser, un conocer y un querer. No se trata de que el obrar siga al ser. Por el contrario, el ser sigue al obrar: la realidad del hombre es la acción, su obrar.

13 Cfr. Felice Bataglia, Alcune Osservazioni sulla Struttura e sulla Funzione del Diritto, 1955; Corso de Filosofia del Diritto, dos vols. $4^{\text {a }}$ ed. 1960 y 1962.

14 Cfr. Giacomo Perticone, Theorie du Droit, 1940; In Tema de Diritto e Giustizia, 1961 . 
La acción del hombre es la acción libre. El ser como actividad y el ser como pensamiento plantean al ser humano la tarea y la exigencia de la elección. ${ }^{15}$ Así pues, la acción opera una elección entre los contenidos posibles.

La acción jurídica comienza con el reconocimiento de un conjunto de normas vigentes; y se desenvuelve y se realiza con la elaboración de normas articuladas entre sí, las cuales deben ser afirmadas como normas positivas en la sociedad a la cual pertenecemos, y las cuales se espera ir siempre reconstruyendo de nuevo.

La libertad de elección y de valoración, frente al Derecho positivo vigente, se le ha reconocido siempre al legislador. Pero no hay ninguna razón para no reconocérsela, para negársela al jurista, en la medida en que éste, cuando emprende la reconstrucción del orden jurídico positivo, su individualización y su dinamización, adopta respecto de éste una posición crítica. Aunque el jurista esté ligado por los principios del ordenamiento jurídico positivo, busca un criterio de justicia, no sólo dentro de este ordenamiento sino también más allá de éste.

A la experiencia jurídica pertenece la conciencia de la tensión que a veces se percibe entre la estricta legalidad, por una parte, y, por otra, la justicia sentida o concebida como debida. La conciencia de las deficiencias e imperfecciones de la realidad, en que vivimos, estimula una obra de superación. El desenvolvimiento del Derecho es el desarrollo de las relaciones interhumanas como un processum ad infinitum.

\section{I) Giuliani}

Alessandro Giuliani ${ }^{16}$ ha investigado sobre el tema de la "experiencia jurídica". El Derecho no está "dado" como algo externo y extraño a la jurisprudencia, la cual vaya a trabajar sobre él. El Derecho, lejos de ser el presupuesto previo de la ciencia jurídica, es en parte el resultado de ésta. La ciencia jurídica, incluso aquella dominada por prejuicios positivistas, ha intuido que en el iusnaturalismo hay principios válidos $\mathrm{y}$ los ha hecho operantes.

Según Giuliani, hay una experiencia jurídica, especifica, irreductible a otras experiencias, y está dotada de una unidad inescindible entre forma y contenido.

Aunque la ciencia y la técnica jurídicas operen con instrumentos conceptuales, éstos sirven para interpretar el objeto Derecho, en el que se

15 Adviértanse algunas similitudes entre este pensamiento de Perticone y la filosofía de la vida de José Ortega y Gasset y de mi concepción de que "el hombre es libre albedrio".

16 Cfr. Alessandro Giuliani, Ricerche in Tema di Esperienza Giuridica, 1957. 
reflejan algunas constantes de la naturaleza humana $y$, por lo tanto, hechos e instituciones que se repiten. La norma jurídica no está dada de una vez, sino que ella es el resultado de la colaboración de la ciencia con las soluciones de la experiencia, las cuales son siempre nuevas, individuales, históricas. La interpretación no es una operación lógica, sino que es sobre todo una valoración de intereses. En tanto que la ciencia del Derecho participa en la creación de su objeto, al estudiar la experiencia jurídica, sus conceptos reflejan las constantes de la experiencia.

La experiencia jurídica vuelve una y otra vez a plantear los mismos problemas prácticos, en función de la historia.

La función de interpretar, que corresponde al jurista, no se agota en volver a conocer una manifestación de pensamiento, sino que va más allá, para integrar y realizar esa manifestación en la vida social, con el fin de tratar los conflictos de intereses que se dan en ésta. Así, intelecto y voluntad cesan de ser términos en contraposición. El intérprete debe mirar siempre al resultado práctico.

J) Alusiones a otros iusfilósofos (Reale, Czerna, Gusmäo, Terán Mata, Garcia Máynez, Cahn y Bagolini)

El presente trabajo está somętido a unos límites de extensión, que su autor no puede rebasar. Por eso, no cabe exponer aquí algunas ideas de otros iusfilósofos, las cuales entiendo que son relevantes para el esclarecimiento del tema de la experiencia jurídica. Pero si no cabe relatar aquí, ni siquiera en concentrado resumen, esas ideas, es imperativo de justicia el que, por lo menos, se las mencione.

En la filosofía jurídica producida por Miguel Reale ${ }^{17}$ hay puntos de enorme alcance para lograr un concepto más depurado de la experiencia jurídica. Entre esos puntos figuran: $A$ ) Su concepción tridimensional del Derecho -que yo, con algunos retoques, he incorporado a mi propio pensamiento. B) La constante renovación de las interpretaciones de la experiencia humana, cada vez con nuevas perspectivas, en un continuo dinamismo, de modo que la universalidad de los problemas no puede contar con resultados definitivos de validez universal y necesaria. Esto, sin embargo, no impide que se vaya produciendo un acercamiento a la verdad total. $C$ ) La tesis de que es misión de la filosofía del Derecho el analizar críticamente la experiencia jurídica, entendiendo el Derecho en su realidad plenaria, y circunscrito por la realidad de la cual emerge, y para la cual se produce; por lo tanto, entenderlo dentro de una experiencia social transida de significaciones axiológicas. D) La producción de cada norma se halla inserta

17 Cfr. Miguel Reale, Filosofia do Direito, 2 vols., $3^{\text {a }}$ ed. revisada y aumentada, 1962. Véase: Recaséns Siches, ob. cit., págs. 553-575. 
como un momento en un proceso, siempre abierto al advenimiento de nuevos hechos y de nuevas valoraciones.

En este contexto debe recordarse también algunas aportaciones de $\mathrm{Re}$ nato Cirell Czerna, ${ }^{18}$ de Paulo Dorado de Gusmão, ${ }^{19}$ y sobre todo de Juan Manuel Terán Mata. ${ }^{20}$

Se debe tomar también en cuenta lo que García Máynez 21 llama “desarrollo dialéctico de la idea jurídica", el cual conduce a la creación de una instancia, que si bien tiene como meta la realización de unos ideales, se ve forzada a negarlos como criterios ultra-positivos de valoración. Pero este dualismo aparece como posición transitoria y relativa de los momentos iniciales de un solo desarrollo, que encuentra su culminación en la sintesis superadora del dualismo entre validez intrínseca y validez formal.

Asimismo se debe consagrar preferente atención a los caudales de ins. piración que para el tema de la "experiencia jurídica" hallamos en la doctrina de Eclmond Cahn sobre "el sentido de la injusticia".22

También pueden ser muy fecundos algunos pensamientos de Luigi Bagolini sobre la "simpatía indirecta como instrumento de interpretación y de comunicación entre diversas visiones de la justicia". ${ }^{23}$

5. Ensayo de algunas puntualizaciones y de algunos esclarecimientos sobre los temas de la experiencia juridica.

Mucho de lo que precedentemente he expuesto en el presente artículo constituye la alusión a una serie de reflexiones -de varios iusfilósofoslas cuales me parece que contienen valiosos estímulos y presentimientos, para aclarar un nuevo concepto de "experiencia jurídica". Se trata del concepto de la realidad en la cual, por la cual y para la cual se produce y se desenvuelve el Derecho, en todas sus fases, desde la gestación consuetudinaria y la legislativa, hasta la individualización jurisdiccional y la doctrina - la científica y la filosófica. Porque en cada uno de los pensamientos ajenos aquí expuestos o aludidos creo ver incitaciones aprovechables a fecundas, por eso me he ocupado de esos variados pensamientos. Sin embargo, por otra parte, muchos de esos pensamientos ajenos, a los cuales me

18 Crr. Renato Cirell Czerna, A Justiça como Historia, 1952. Véase: Recaséns Siches, ob. cil., págs. $57^{1-573}$.

19 Cfr. Paulo Dourado de Gusmāo, Curso de Filosofia do Direito, 195o; Introduçae a Ciencia do Direito, $2^{7}$ ed., 1960 . Véase: Recaséns Siches, ob. cit., págs. 567-57o.

20 Cir. Juan Manuel Terán Mata, Filosofia del Derecho, 2a ed. 1964.

21 Cfr. Eduardo Garcia Máynez, La Definición del Derecho: Ensayo de Perspectivismo Juridico, $2^{\text {a }}$ ed., 1960 .

22 Cfr. Edmond Cahn, The Sense of Injustice, 1949. Véase: Recaséns Siches, ob. cit., págs. $680 \cdot 697$.

23 Cfr. Luigi Bagolini, Il significato della persona nell'esperienza giuridica e sociale, 1946; Grustizia distributtiva e Simpatia, 1954; Descrittiva pura del dato giuridico, 1956. Véase una amplia cxposición del pensamiento de Bagolini en Recaséns Siches, ob. cit., págs. $982-993$. 
he referido, me parecen todavía "verdes", inmaturos, a veces desdibujados o difuminados, algo confusos, o, por lo menos, poco rigorosos, imprecisos. Antójanseme más bien como valiosos barruntos o presentimientos, pero que necesitan una serie de clarificaciones y de delimitaciones.

Declaro muy estrictamente que yo no creo poder presentar aquí ya una concepción madura y total de la "experiencia jurídica", en el nuevo sentido de esta expresión, al que he venido aludiendo. Pero quizá pueda ofrecer algunas aclaraciones y puntualizaciones, que contribuyan a una mejor inteligencia de este concepto.

Por de pronto y ante todo, adviértase que se trata de averiguar una experiencia especial, la cual opera como factor o como fuente en la generación y en el desenvolvimiento del Derecho en términos generales, y en la producción de las normas jurídicas de toda especie -genéricas, particulares e individualizadas-; y también como estímulo y directriz orientadora en la crítica estimativa y en la filosofía de los valores jurídicos.

En un primer acercamiento de conjunto a esa "experiencia jurídica", yo la describiría en los siguientes términos. Si hablamos de "experiencia" en este caso, es porque nos hallamos ante algo dado. Ahóra bien, eso dado, que constituiría la "experiencia jurídica", es un conjunto muy complejo, pero unitario, de diversos datos, los cuales están recíprocamente entretejidos. Ese conjunto de datos, complejisimo pero unitario, consiste en unos hechos de relaciones interhumanas, propiamente sociales, hechos en los que encarna una dimensión conflictiva, es decir, una tensión dramática, un choque entre diversas aspiraciones humanas, y de éstas con las limitaciones de la realidad. Esas aspiraciones están relacionadas no sólo con necesidades y deseos, sino que, además, están cargadas con referencias a valoraciones, todo lo cual plantea, quiérase o no, perentoriamente, un problema práctico, que está demandando un tratamiento y una solución. Esa experiencia es, por lo tanto, una experiencia a la vez de realidades, tal y como ellas son, y de ideas, afanes, necesidades; porque esas realidades no son simples realidades frías, sino realidades vistas ya directamente a través de lentes estimativos; realidades que, entre otros componentes de esas mismas realidades, incluyen como ingredientes de ellas unas valoraciones -creencias y convicciones estimativas-, diferentes a veces en los varios interesados, profesadas por los diversos hombres y grupos involucrados en esos hechos conflictivos. $Y$ tal experiencia incluye también, y, además, el hecho de que quienes profesan esas estimaciones o propugnan determinadas aspiraciones ideales pretenden que éstas concuerdan con criterios de valor objetivamente válidos. $\mathrm{Y}$ tales hechos, dotados de tan complejas y variadas dimensiones -intimamente trabadas entre sí- se presentan como problemas prácticos que requieren solución, como necesidades efectivamente sentidas por las gentes implicadas en esas realidades, que demandan satisfacción, lo cual, 
además, se siente y se piensa como imprescindible para la subsistencia y la buena marcha de la sociedad concreta en la que emergen esas cuestiones.

Se trata no de una experiencia fría, mera conciencia de datos tal y como ellos son; sino que se trata, diríamos, de una conciencia caliente, de la conciencia de un drama, de la conciencia de conflictos, de la conciencia de aspiraciones, de entusiasmos por ciertos ideales, del ímpetu de determinadas aspiraciones, de determinados deseos. Y se trata, al mismo tiempo, de la conciencia dolorosa de penurias, de dolores, de desajustes, de inquietudes. $Y$ se trata también conjuntamente de un afán de certeza y de seguridad que venga a aquietar la ansiedad de la incertidumbre, y a aliviar el dolor de la inseguridad; pero esto, no de cualquier manera, sino precisamente de acuerdo con lo que se considera como exigencias de justicia.

Por lo tanto, se trata de una experiencia cuyos datos son variados, pero todos ellos en estrecho entrelace: de datos de realidades sociales; de datos dentro de esas realidades que consisten en sentimientos de escasez, a veces de carencia, en apuros, en dolores, protestas, anhelos, afanes, programas, en intuiciones de justicia en las personas afectadas; de ideas de justicia en los sujetos principales de esa experiencia - por ejemplo, en el legislador y en el juez-; del choque de intereses contrapuestos -en ocasiones, unos que parecen legítimos y otros ilegítimos; pero en otras ocasiones, entre dos intereses ambos legítimos, aunque no pueden ser satisfechos por completo los dos-; del peso propio de determinadas realidades sociales, por ejemplo de algunos hechos económicos, que siguen sus propios mecanismos, o de la influencia de añejas tradiciones, o de la inercia de ciertas rutinas.

En suma, se trata de la experiencia de problemas prácticos de convivencia y de cooperación interhumanas, erizados de dificultades; problemas que demandan un tratamiento adecuado y una solución, al menos relativa, de acuerdo con pautas de justicia, conforme a criterios de valor. Esos problemas prácticos, por ser tales, en tanto que tales, consisten en colisiones, en disputas, que requieren ser solventadas prácticamente; y precisamente ser solventadas de modo ejecutivo, es decir, no tan sólo ser resueltas en el plano de la teoría, sino al nivel de la realidad efectiva, de modo terminante y perentorio, de manera firme y decisoria, impositiva.

Esta experiencia es la que en términos generales engendra la producción de todo Derecho; y la que en cada caso opera como estímulo para la producción de cada una de las normas jurídicas - lo mismo de las legalidades, qúe de las reglamentarias, que de las particulares de los negocios jurídicos, que de las sentencias judiciales y de las resoluciones administrativas.

Expresando lo mismo desde otro punto de vista, la producción del Derecho no sigue el camino que muchos iusfilósofos -sobre todo de la época del Iluminismo o Ilustración - imaginaron; no sigue el camino constante en que el legislador, por ejemplo, comience por meditar sobre la 
justicia, descubrir la idea de ésta, derivar luego de la misma conclusiones consistentes en principios generalísimos; proceda después a deducir consecuencias de esos principios generales; y, por fin, aplicarlos a unas realidades sociales concretas, elaborando de esta manera una especie de sistema juridico. Esto es, la producción del Derecho no se desenvuelve desde arriba hacia abajo por via de deducciones, mediante la construcción de un sistema. Por el contrario, tiene lugar en dirección opuesta: la producción arranca de la experiencia jurídica en los términos en que acabo de describirla -aunque sólo abocetadamente. Esa experiencia jurídica estimula al encargado de fabricar las normas - generales o individualizadas - a ponderar los factores en conflicto, y a hacer esto a la luz de unos criterios estimativos: pero, al mismo tiempo, a la luz de las posibilidades efectivamente viables que la realidad social ofrece. Y tanto el legislador como el juez deben también tratar de anticipar mentalmente cuáles vayan a ser probablemente los efectos reales de las normas que dicten.

Esa experiencia jurídica es la fuente que dispara la producción del Derecho, tanto la legislación, como la jurisprudencia; y también los programas, o ideales axiológicos o estimativos, concretos.

Esta constatación contribuye a reafirmar y a proyectar nueva iluminación a la tesis que cada día obtiene renovada y más extensa adhesión de que las operaciones mentales del legislador, del juez, del jurisconsulto y del filósofo del Derecho no constituyen un pensamiento sistemático, sino un pensamiento sobre problemas, un pensamiento aporético. Es decir, tenemos que habérnoslas con un pensamiento que no parte de primeros principios como premisas, para extraer consecuencias, sino que arranca del análisis de problemas prácticos suscitados por la vida social, los analiza en cuanto a todos los factores y todas las dimensiones que ellos contienen, los pondera mediante el examen de los diferentes argumentos contrarios que las partes interesadas aducen, los valora a la luz de criterios de justicia y de prudencia, y trata de hallar la solución que a la vez sea la más justa -inevitablemente en términos relativos-, la más prudente, y la más viable, habida cuenta de todas las circunstancias que concurren en tales problemas - circunstancias que son diversas en cada situación social, y que además son cambiantes. Cierto que ésta fue la tesis sostenida por Aristóteles, por Cicerón, practicada por la jurisprudencia romana, también por los juristas de la Edad Media, y restaurada por Vico. Pero, además, esta tesis - abandonada, con fracaso, bajo la influencia del espíritu cartesianoha sido reivindicada, reforzada, en nuestros días, por varios iusfilósofos, principalmente por Viehweg ${ }^{24}$ y por Perelman, ${ }^{25}$ y por mí mismo; y es

24 Cfr. Theodor Viehweg, Topik und Jurisprudenz, 1953. Véase Recaséns Siches, ob. cit., tomo II, págs. 1060-1080.

25 Cfr. Ch. Perelman, Traité de l'argumentation (en Collaboration avec Mme. L. 
además la tesis que va consiguiendo cada día más amplia aceptación entre los nuevos juristas, principalmente por una pléyade de jóvenes civilistas alemanes muy ilustres, tales como, por ejemplo, Fritz von Hippel, Joseph Esser, Walter Wilburg, quienes coinciden en sostener que la jurisprudencia no debe pretender construir sistemas, pues su misión consiste en el propósito de hallar soluciones justas a los problemas prácticos planteados - tanto al nivel de la legislación, como al nivel de la jurisdicción- orientándose por criterios iusnaturalistas en conjugación con las realidades concretas.

Hasta aquí he presentado el cuadro global de la "experiencia juridica"; como un complejo conjunto y unitario de datos, que constituyen la conciencia de un problema práctico, cargado de una especie de incitación dinámica, esto es, de estímulos, para buscar el tratamiento más adecuado y la solución relativamente mejor de ese problema práctico. Ahora bien, después de constatar la presencia del problema con totalidad global, convendría proceder al análisis de los diferentes datos que integran ese problema. Aunque tales datos se hallen integrados recíprocamente entre sí, se puede por vías mentales de abstracción, proceder al examen de cada uno de los varios tipos de datos. Dentro de los márgenes limitados de este trabajo no cabe emprender un análisis exhaustivo de todos los tipos de esos datos. Me limitaré a hacer unas pocas observaciones tan sólo sobre algunos de los tipos de datos que hallamos en el complejo total de la "experiencia juridica

Pues bien, entre los datos de esa "experienecia jurídica", figuran los hechos de que algunos términos del problema se presentan como el sentimiento de "sentirse autorizado", "justificado" para reclamar o exigir algo que se presenta como debiendo ser "lo suyo", frente a algunas de las partes envueltas en el problema, es decir, se presentan bajo la forma del sentimiento o de la intuición de un "derecho subjetivo", que debiera ser reconocido o garantizado por el ordenamiento. Respecto de este punto, creo que Luis Legaz y Lacambra ${ }^{26}$ ha aportado aclaraciones muy importantes. Observa certeramente Legaz y Lacambra que el sentido originario de la palabra Derecho no es el de norma. El sentido originario del ius es el de un poder o una autorización, o una facultad con que, al usarse, no se hace un daño a otro, antes bien se afirma lo que es de uno $-\mathrm{y}$ esto sentido o pensado como algo con validez intrínseca, justificada en la naturaleza del hombre, entendida ésta en sentido teleológico ideal. Es decir, se presenta como Derecho natural, que consiste primariamente en un derecho subjetivo - como la realidad de la libertad inherente a la persona-, sin perjuicio

Olbrechts-Tyteca), 1958; Justice et Raizon, 1963; The Idea of Justice and the Problem of Argument, 1963. Véase mi amplia exposición del pensamiento de Perelman: Recaséns Siches, ob. cit., tomo II, págs. $1045^{-1059}$.

26 Cfr. Luis Legaz y Lacambra, La Realidad del Derecho, 1963. 
de que esto se traduzca o reduzca después a una norma, aunque, con ello, tal principio sufre ya limitaciones.

A estas observaciones creo que debiera añadirse otro dato, que es algo así como el reverso en otra persona de ese sentimiento o intuición del "derecho subjetivo natural", a saber, el dato que Petrazycki ${ }^{27}$ describe como el "sentirse obligado a darle o reconocerle a otro algo que pertenece a ese otro, algo que le debemos, algo que ese otro puede exigirnos"; a diferencia del sentimiento de la obligación moral, en el cual aquello a lo cual nos consideramos obligados no consiste en algo que debamos a otro sujeto como propio de éste, y que éste pueda reclamárnoslo, antes bien, en algo que tenemos la obligación de otorgarle, de donarle, por virtud de una decisión que depende tan sólo de nuestra buena voluntad $\rightarrow$ sin perjuicio de que moralmente estemos ligados a mostrarle tal buena voluntad.

Otro tipo de comentario que es pertinente hacer sobre la "experiencia jurídica" es el siguiente. Las inspiraciones que de ésta manan suelen presentarse las más de las veces de un modo negativo, es decir, como reacción de nuestra conciencia ética contra algo que sentimos como injusto, es decir, a través de lo que Edmond Cahn ${ }^{28}$ llama "el sentido de la injusticia". Se trata de un viejo pensamiento, apuntado ya por Schopenhauer, en alguna medida por Richard Loening, ${ }^{29}$ pero que Edmond Cahn ha desenvuelto a fondo, muy certeramente, y sacando del mismo consecuencias de largo alcance. Mientras que es difícil el hallazgo de lo que la justicia sea, en términos generales, en cambio, la reacción de la conciencia contra un caso, real o imaginario, de injusticia suele presentarse con facilidad, como un juicio evidente, inmediato. $Y$ este "sentido de la injusticia" referido a un caso concreto, o suscitado por éste, por de pronto nos señala con evidencia lo que no debe hacerse, lo que no puede admitirse, por ser evidentemente injusto; y sobre la base de esta constatación, puede resultar más fácil la búsqueda de la solución justa y viable.

Creo que, con lo expuesto en esta última parte del presente estudio, he contribuido a aclarar un poco la realidad que los pensadores antes referidos presintieron o barruntaron más o menos confusamente; y a precisar el alcance que esa realidad tenga para explicar y entender la producción del Derecho en el seno de la vida humana social, y, al mismo tiempo, para iluminar otros muchos temas básicos de la Filosofía del Derecho.

Debo hacer constar de modo taxativo que con el presente trabajo no pretendo ni remotamente haber ofrecido un estudio suficiente sobre la "experiencia jurídica". Creo tan sólo que quizá me haya sido dado lograr un

27 Cfr. L. Petrazycki, Ueber die Motive des Handels und über das Wesen der Moral und des Rechtes (trad. alemana del original ruso por Balso), 1907.

28 Cfr. Edmond Cahn, ob. cit.

29 Cfr. Richard Loening, Ueber Wurzel und Wesen des Rechtes, 1907. 
poco más de claridad en este tema, haber contribuido a ubicarlo en el lugar que le corresponde, y haber mostrado las mejores vías para emprender un estudio más a fondo y un análisis más detallado de este asunto, que puede, y aún debe, ocupar un puesto central en la Filosofía del Derecho.

LUIS RECASÉNS SICHES 